\title{
Evaluation of Immune Responses to Influenza Vaccination in Chronic Obstructive Pulmonary Disease
}

Julie G Burel ${ }^{1}$, Karthik Nath ${ }^{1}$, Antonia L Pritchard ${ }^{1}$, Olivia J White ${ }^{1}$, Janet M Davies ${ }^{1}$, Michelle Towers ${ }^{2}$, David Looke ${ }^{1,2}$ and John W. Upham ${ }^{1,2 *}$

${ }^{1}$ School of Medicine, The University of Queensland, Brisbane, Australia

${ }^{2}$ Princess Alexandra Hospital, Brisbane, Australia

\begin{abstract}
Background: Given that viral infections are common triggers for exacerbations of Chronic Obstructive Pulmonary Disease (COPD), current clinical guidelines recommend that all patients receive annual influenza vaccinations. A detailed examination of the immune response to vaccination in COPD has not previously been undertaken, so this study aimed to compare immune responses to influenza vaccination between COPD patients and healthy subjects.

Methods: Twenty one COPD patients and fourteen healthy subjects were recruited and cellular immune function was assessed pre- and post- vaccination with trivalent inactivated influenza vaccine.

Results: One month after vaccination, H1N1 specific antibody titres were significantly lower in COPD patients than in healthy controls $(p=0.02)$. Multivariate analysis demonstrated that post vaccination antibody titres were independently associated with COPD, but not with age or smoking status. Innate immune responses to the vaccine preparation did not differ between the two populations. Serum concentrations of IL-21, a cytokine that is important for B cell development and antibody synthesis, were also lower in COPD patients than in healthy subjects $(p<0.01)$. In vitro functional differences were also observed, with fewer proliferating B cells expressing CD27 ( $p=0.04)$ and reduced T-cell IFN- $\gamma$ synthesis $(p<0.01)$ in COPD patients, relative to healthy subjects.
\end{abstract}

Conclusions: In conclusion, COPD was associated with altered immune responses to influenza vaccination compared to healthy controls with reductions in both T-cell and B-cell function. These findings provide a foundation for future research aimed at optimising the effectiveness of influenza vaccination in COPD.

Keywords: Chronic Obstructive Pulmonary Disease (COPD); Influenza virus; Innate and adaptive immune response; Vaccination

\section{Introduction}

Chronic Obstructive Pulmonary Disease (COPD) is responsible for an increasing burden of disease throughout the world, such that by 2030, the World Health Organization (WHO) estimates that COPD will become the third leading cause of death worldwide [1]. In high income countries, tobacco smoke is the biggest risk factor for COPD, while in low-income countries, indoor air pollution, especially exposure to smoke from cooking stoves, is a major risk factor for COPD [1]. Acute exacerbations of COPD frequently result in hospitalization, and are responsible for a substantial burden on patients and the health care system [2]. These exacerbations are often triggered by bacterial or viral infections [3-5], and COPD patients are known to be at particular risk of complications arising from seasonal influenza viruses [6]. Finding effective ways to prevent respiratory infections in COPD is an important priority.

Given the exacerbations of COPD resulting from viral infections, current guidelines recommend that all COPD patients be vaccinated against seasonal influenza each year [6-8]; however, the effectiveness of this strategy is somewhat controversial. While observational studies report less frequent COPD exacerbations, pneumonia, hospitalisations and lower mortality rates in vaccine recipients [9-11], there is increasing recognition of the 'healthy user effect' whereby vaccine recipients may also exhibit a variety of lifestyle factors, health seeking activities and adherence to medical advice that in themselves lead to better health outcomes [11-13]. Some also report that influenza vaccination is associated with better health outcomes in summer, when influenza virus does not usually circulate, suggesting that the apparent benefits reported in observational studies may be subject to unidentified confounding factors [14]. A recent Cochrane review noted that relatively few Randomized Controlled Trials (RCTs) have studied influenza vaccination in COPD [15]. Although two RCTs reported that vaccination reduces influenza-related COPD exacerbations, both studies were performed in populations with a low rate of prior vaccination, and no reduction in hospitalization or mortality was observed $[16,17]$.

Surprisingly little information is available on the extent to which influenza vaccination can induce satisfactory adaptive immune responses in COPD. Studies of vaccine immunogenicity have the potential to uncover factors associated with a poor vaccine response and provide information to guide future research aimed at improving vaccine effectiveness, particularly in at-risk patient groups. Following vaccination in healthy individuals, virus specific B cells proliferate, differentiate into memory $\mathrm{B}$ cells and plasma cells and produce antibodies to influenza haemagglutinin (HA) and neuraminidase [18]; there is strong evidence that the concentration of anti-HA antibodies is correlated with protection against influenza [19-21]. T cells are also important for host defence against influenza, killing infected target

*Corresponding author: Professor John Upham, School of Medicine, The University of Queensland, Level 3, R Wing, Princess Alexandra Hospital, Woolloongabba, Brisbane QLD 4102, Australia, Tel: +61 73176 5717; Fax: +61 7 3176 3265; E-mail: j.upham@uq.edu.au

Received May 29, 2012; Accepted June 04, 2012; Published June 10, 2012

Citation: Burel JG, Nath K, Pritchard AL, White OJ, Davies JM, et al. (2012) Evaluation of Immune Responses to Influenza Vaccination in Chronic Obstructive Pulmonary Disease. J Vaccines Vaccin S4:001. doi:10.4172/2157-7560.S4-001

Copyright: $\odot 2012$ Burel JG, et al. This is an open-access article distributed under the terms of the Creative Commons Attribution License, which permits unrestricted use, distribution, and reproduction in any medium, provided the original author and source are credited. 
cells, limiting viral replication and providing help to B cells [22,23]. Innate immune response to influenza virus leads to the production of type I IFN (IFN $\beta$, IFN $\alpha$ ) and the expression of interferon inducible genes such as MxA and OAS [24]. The cytokines IP-10 and IL-12 are also known to be produced after influenza virus exposure [25]. These innate factors have a significant role in the vaccine protection mediated by adjuvants [26].

The objective of this study was to assess the immune response to influenza vaccination in COPD patients and healthy controls subjects. Persistent colonization of airways by pathogens may contribute to a chronic activation state and COPD patients may be less able to mount an effective immune response toward Influenza vaccination. Based on our initial observation that serum vaccine specific H1N1 antibodies titres were lower in COPD patients than in healthy controls, we sought to determine the mechanisms underlying the humoral, innate or adaptive immune function that might be involved.

We measured IL-21, a cytokine that is known to have a role in B cell development and antibody production [27-29] and which is readily measured in serum [30]. Innate immune response of the vaccine preparation was assessed in vitro using peripheral blood mononuclear cells (PBMC) collected prior to vaccination. B-cell and T-cell function were assessed in vitro using vaccine-stimulated $\mathrm{PBMC}$ collected before and after vaccination. Our findings indicate that COPD is associated with reductions in vaccine-specific $\mathrm{T}$ cell and $\mathrm{B}$ cell function relative to healthy individuals while innate immune response to the vaccine preparation was unchanged.

\section{Material and Methods}

\section{Study population}

The study was approved by the Princess Alexandra Hospital Human Ethics Committee and written informed consent was obtained from all participants who completed an extensive questionnaire and performed spirometry according to ATS/ERS criteria. Stable COPD patients with an $\mathrm{FEV}_{1} / \mathrm{FVC}$ ratio $<0.7$ were recruited from the respiratory outpatient clinic, while healthy subjects were spouses of patients and hospital staff. Exclusion criteria (for healthy controls and COPD subjects) included respiratory infection or COPD exacerbation within the preceding 4 weeks, malignancy within the preceding 2 years and hypersensitivity to egg proteins. Between March and August 2010, all participants received a single dose of purified, inactivated, split virion influenza vaccine (Fluvax ${ }^{\oplus} 2010$, Lot B0906-27902, CSL Biotherapies, Parkville, Australia) as a deep subcutaneous injection (16 mm needle) in the deltoid region of the arm. This vaccine contained the A/California/7/2009 H1N1-like, A/Perth/16/2009 H3N2-like and B/Brisbane/60/2008-like influenza strains (15 $\mu \mathrm{g}$ HA per strain).

\section{Blood samples}

Blood was collected from all participants 28 days after vaccination (T1; $\mathrm{n}=14$ healthy controls, $\mathrm{n}=21$ COPD patients); some participants also had blood collected before vaccination (T0; $\mathrm{n}=10$ healthy controls, $\mathrm{n}=7$ COPD patients). Plasma and serum were stored at $-20^{\circ} \mathrm{C}$ while PBMC were isolated and used immediately, or cryopreserved in liquid nitrogen for later use as previously described [31]. Pre vaccination cells were used to assess the innate immune response to the vaccine preparation. Post vaccination cells were used to assess the adaptive immune response and the memory function by restimulating the cells in vitro with the vaccine, to create an artificial re-exposure to the virus.

\section{Serum influenza specific antibodies and IL-21}

Serum H1N1-specific antibodies (Abs) were measured by haemagglutination inhibition assay in a regional reference serology laboratory (Prince of Wales Hospital, Randwick NSW). Serum IL-21 was quantified using a commercial ELISA kit (eBiosciences, San Diego, CA) according to the manufacturer's instructions. Samples were tested undiluted; the lower limit of detection was $15.5 \mathrm{pg} / \mathrm{ml}$.

\section{In vitro cellular immune responses}

PBMC $\left(10^{6}\right.$ cells $\left./ \mathrm{mL}\right)$ were stimulated in vitro with influenza vaccine for five days as detailed in the Supplementary Methods. Supernatant was collected at $24 \mathrm{~h}$ (IP-10/CXCL10 and IFN- $\alpha$ ) and at 5 days (IFN- $\gamma$ ) for cytokine measurement by ELISA (see Supplementary Methods). Limit of detection were $3.9 \mathrm{pg} / \mathrm{ml}$ for IP-10, $9.7 \mathrm{pg} / \mathrm{ml}$ for IFN- $\alpha$ and $7.8 \mathrm{pg} /$ $\mathrm{ml}$ for IFN- $\gamma$. Lymphocyte proliferation was assessed by flow cytometry with the vital dye Carboxy Fluorescein diacetate Succinimidyl Ester (CFSE; Sigma, Taufkirchen, Germany). Briefly, PBMC were labelled with CFSE (final concentration of $1 \mu \mathrm{M}$ ) as described elsewhere [32] and stimulated in vitro with influenza vaccine for five days. Surface staining with anti-human CD19 (eBiosciences) and anti-human CD27 (Becton Dickenson) was used to identify the phenotype of cells which were $\mathrm{CFSE}^{\text {low }}$ and had thus divided in response to influenza vaccine. Additional experimental details are provided in the online data supplement.

RNA from influenza vaccine stimulated PBMC was reverse transcribed using Transcriptor first strand cDNA synthesis kit (Roche Applied Science), according to manufacturer's instructions. IFN- $\gamma$, interferon-inducible $\mathrm{Mx} \mathrm{A}$ (MxA; also known as $\mathrm{Mx} 1)$, 2',5'-oligoadenylate synthetase (OAS1) and IL-12p35 gene expression were investigated by quantitative real time PCR (qPCR), using $U B E 2 D 2$ as the reference gene. UBE2D2 was initially identified as a stable reference gene in CD4+ cells [33] and subsequently assessed in-house to be stably expressed in total PBMC in the absence and presence of influenza vaccine. qPCR was performed using the LightCycler 480 (Roche Applied Science, Indianapolis, USA) with GoTaq SYBR green (Promega, Madison, USA). Data were analysed using the Pfaffl method [34] and results expressed as a ratio of stimulated to control (unstimulated) samples, with a fold change of 1 representing unstimulated expression levels. Primers sequences used for amplification are available in Supplementary Table 1.

\section{Statistical analysis}

Initial statistical analyses were performed using GraphPad Prism software, version 6.0. Normality, univariate and multivariate linear regression analyses were calculated with SPSS version 17.0 statistical

\begin{tabular}{|l|c|c|c|}
\hline \multicolumn{1}{|c|}{ Characteristic } & COPD patients & Healthy controls & $\mathrm{p}$ value \\
\hline Subjects & 21 & 14 & \\
\hline Pre vaccination sample (T0) & 7 & 10 & \\
\hline Ages (years; mean[range]) & $66(38-80)$ & $54(36-86)$ & $0.01^{\#}$ \\
\hline Gender (M/F) & $14 / 7$ & $8 / 6$ & $0.57^{\&}$ \\
\hline Body Mass Index (mean[range]) & $26(13-33)$ & $27(21-32)$ & $0.80^{\#}$ \\
\hline Previous vaccination & $76 \%(16 / 5)$ & $79 \%(11 / 3)$ & $0.35^{\&}$ \\
\hline Co-morbidity* & $29 \%(6 / 15)$ & $14 \%(2 / 12)$ & $0.18^{\&}$ \\
\hline Smoking history (current or past) & $100 \%(21 / 0)$ & $29 \%(4 / 10)$ & $<0.001^{\&}$ \\
\hline Inhaled steroids & $66 \%(14 / 7)$ & - & - \\
\hline
\end{tabular}

* Presence of hypertension, hyperlipidemia, diabetes or cardiovascular disease \# Unpaired t test

\& Chi squared test

Table 1: Demographic and clinical characteristics. 
Citation: Burel JG, Nath K, Pritchard AL, White OJ, Davies JM, et al. (2012) Evaluation of Immune Responses to Influenza Vaccination in Chronic Obstructive Pulmonary Disease. J Vaccines Vaccin S4:001. doi:10.4172/2157-7560.S4-001

\begin{tabular}{|c|c|c|}
\hline \multicolumn{3}{|l|}{ Univariate analysis } \\
\hline Factor & correlation coefficient $\rho$ & $p$ value \\
\hline Age & -0.431 & $0.011^{*}$ \\
\hline COPD & -0.422 & $0.011^{*}$ \\
\hline Previous vaccination & 0.149 & 0.402 \\
\hline Inhaled steroids & -0.496 & $0.026^{*}$ \\
\hline Smoking & -0.314 & 0.071 \\
\hline IL-21 at day 28 & 0.304 & 0.091 \\
\hline \multicolumn{3}{|l|}{ Multivariate analysis } \\
\hline Factor & correlation coefficient $\beta$ & $p$ value \\
\hline COPD & -0.558 & $0.047^{*}$ \\
\hline
\end{tabular}

*indicates statistical significance

Table 2: Clinical features associated with post vaccination $\mathrm{H} 1 \mathrm{~N} 1$ antibody titres.

software. Kolmogorof-Smirnov testing showed that all the data except age and body mass index (BMI) variables were not normally distributed. Therefore, the non parametric paired Wilcoxon test was used to compare pre and post vaccination variables within the same population; and the non parametric unpaired Mann Whitney test was used to compare variables between COPD subjects and healthy controls within the same time point. Parametric unpaired t-tests were used to analyse age and BMI (as normally distributed). Differences in seroconversion rates were assessed by chi-squared analysis. Univariate and multivariate analysis were used to determine the clinical parameters associated with post vaccination serum $\mathrm{H} 1 \mathrm{~N} 1$ antibody titres. $\mathrm{P}$ values $\leq 0.05$ were considered significant.

\section{Results}

\section{Subject characteristics}

Demographic characteristics of the subjects are outlined in Table 1. All subjects were Caucasian, except for three healthy controls (two south Asians and one African).

All COPD patients had a history of current or past smoking, whereas only four healthy donors were past smokers. COPD subjects were somewhat older than the healthy donors ( $66 \pm 11$ vs. $54 \pm 15$ years old; $\mathrm{p}=0.01$ ). Most COPD subjects had moderate, severe or very severe airflow obstruction according to current GOLD criteria (Supplementary Table 2), while all healthy donors had normal spirometry. Three-quarters of both groups had previously received influenza vaccination. Two thirds of COPD patients were using inhaled corticosteroids at the time of the study while only one patient was using oral prednisolone.

\section{Post-vaccination antibody titres}

Measurement of post vaccination Influenza A/H1N1 strain-specific $\mathrm{Ab}$ titres in serum revealed they were significantly lower in COPD patients than in healthy controls (Figure 1; median Ab titre COPD $=640$; healthy $=1280 ; p=0.02)$. Seroconversion, defined as a fold increase $\geq 4$ in $\mathrm{Ab}$ titre between pre and four weeks post-vaccination [19], occurred in $90 \%$ of healthy controls but in only $43 \%$ of COPD patients $\left(\chi^{2}=4.41\right.$; $\mathrm{p}=0.036$; data not shown). Univariate analysis suggested that post vaccination $\mathrm{Ab}$ titres were significantly associated with age, COPD and inhaled steroids but not with previous vaccination status or smoking history (Table 2). However, multivariate linear regression showed that post vaccination $\mathrm{Ab}$ titre was independently associated with $\mathrm{COPD}$ alone, but not with age, smoking history or previous vaccination. Strong co-linearity between the COPD and inhaled steroid use meant this variable could not be used in the multivariate model. Taken together, these results imply that the low post vaccination $\mathrm{Ab}$ titres in COPD individuals were directly related to COPD per se, rather than being related to these other variables. Given this lower immune response to the H1N1 strain in the vaccine preparation, we therefore sought to evaluate the in vitro immune responses to influenza vaccine in COPD patients compared to healthy controls.

\section{Innate immune responses prior to vaccination}

We next sought to determine if the low post vaccination $\mathrm{Ab}$ titres in COPD individuals might be related to an impaired innate immune response to the vaccine. Thus innate immune responses to the vaccine preparation, prior to vaccination, were assessed in vitro. Stimulation of PBMC with vaccine for 24 hours induced substantial transcription of IFN- $\beta$, the interferon stimulated genes MxA and OAS and the Th1 polarizing cytokine IL-12p35, while analysis of supernatants 24 hours post-stimulation showed production of high concentrations of IFN- $\alpha$ and IP-10 proteins (Table 3). Of the measured innate factors, only IP-10 was significantly higher in the COPD population compared to healthy individuals (Table 3; $\mathrm{p}=0.04$ ). All other outcomes were similar in COPD patients and healthy control subjects.

\section{Serum IL-21 post-vaccination}

We next sought to examine potential factors involved in adaptive immunity that might explain the differences in post-vaccination $\mathrm{Ab}$ titres between COPD patients and healthy donors.

Serum IL-21 concentrations were measured in COPD patients and healthy subjects 28-days post-vaccination. Significantly lower IL-21 was detected in COPD patients compared to healthy controls (Figure

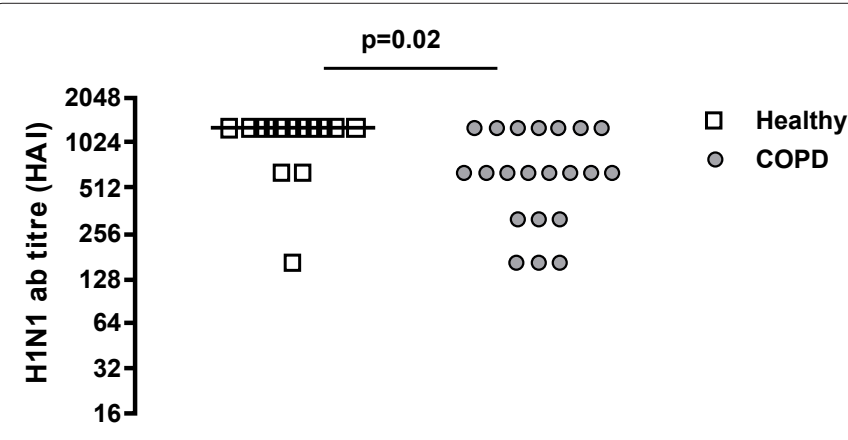

Figure 1: Serum H1N1 vaccine-specific antibody titres. Sera were collected 28 days post vaccination. Post vaccination $A b$ titres were significantly lower in COPD subjects $(n=21)$ than in healthy controls $(n=14 ; p=0.02)$. Horizontal lines refer to median values.

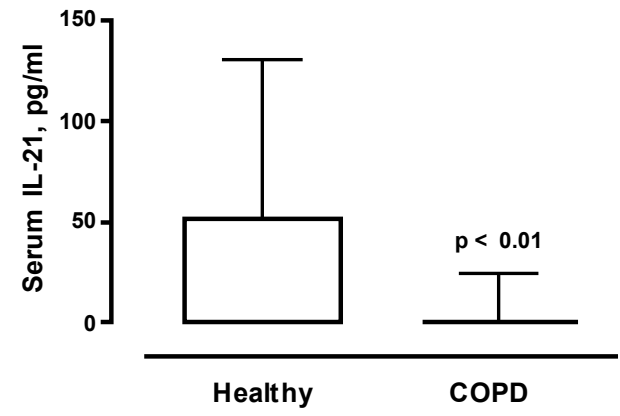

Figure 2: Post vaccination serum IL-21. Sera were collected 28 days post vaccination (T1). Results are shown as median $\pm I Q ; n=21$ COPD subjects and 14 healthy controls. 


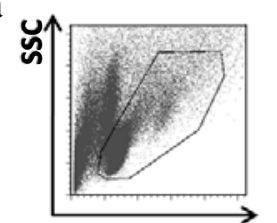

FSC

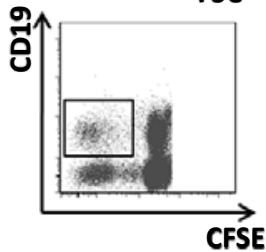

Healthy controls b

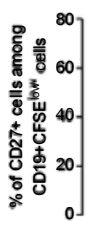

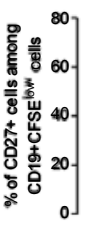
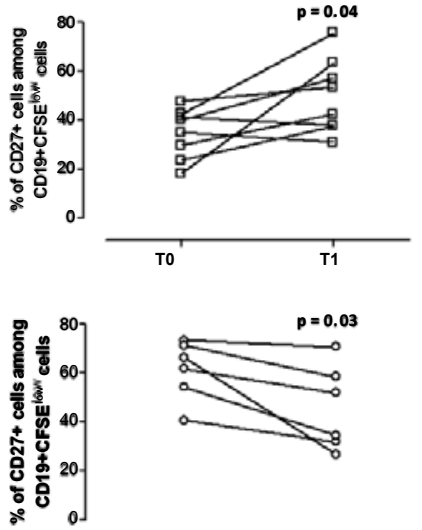

Healthy

controls

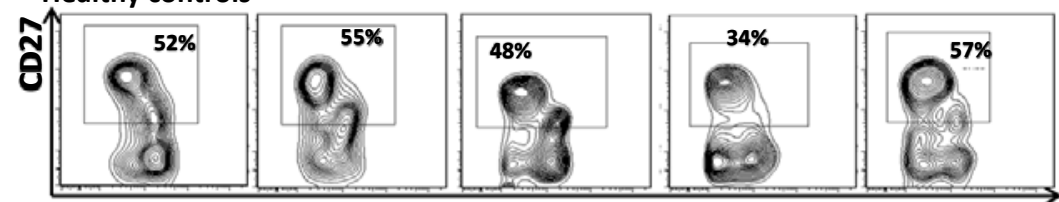

CD19

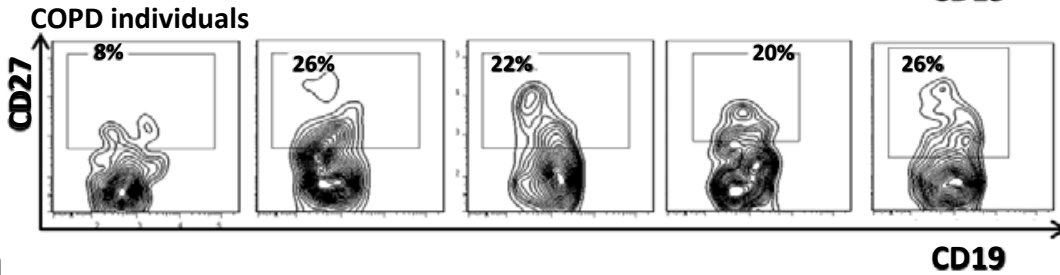

d

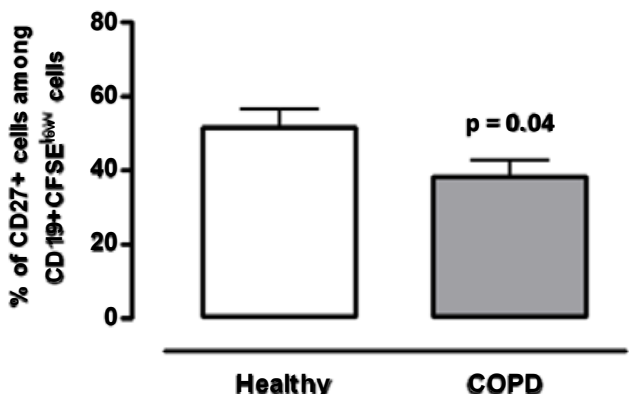

Figure 3: Frequency of proliferating B-cells expressing CD27 after in vitro vaccine stimulation. PBMC were labelled with CFSE and cultured with influenza vaccine for five days. (a) Gating strategy to identify CD19+ proliferating cells (CD19+CFSElow). (b) Pre (T0) and Post (T1) vaccination frequencies of CD27+ cells among CD19+CFSE ${ }^{\text {low }}$ cells; $n=8$ healthy controls, $n=6$ COPD subjects. (c) Examples of CD19 and CD27 expression on CD19+CFSElow cells from PBMC collected post vaccination (T1) from 5 healthy controls (upper panel) and 5 COPD patients (lower panel). Percentages of CD19+CFSElow expressing CD27 are indicated in boxes. (d) The frequency of post vaccination (T1) CD27+ cells among CD19+CFSElow cells; $n=19$ COPD subjects and 12 healthy controls. Results are shown as median \pm IQ.

\section{$2, \mathrm{p}<0.01)$}

\section{Post-vaccination B-cell function in vitro}

In vitro immune functions were examined in a subset of 19 COPD patients and 12 healthy donors, who were matched for age (mean age [range] $=57$ [37-86] for healthy subjects; mean age [range] $=66[38-80]$ for COPD subjects; $\mathrm{p}>0.05$ ), in order to provide insight into possible mechanisms leading to reduced antibody production in COPD. Given the reduced serum IL-21 in COPD, we examined the capacity of B-cells to mount a recall response to the vaccine in vitro, using PBMC obtained before and 28-days post-vaccination. These experiments showed that stimulation of PBMC with influenza vaccine for 5 -days led to the appearance of a distinct population of proliferating
B cells ( $\mathrm{CFSE}^{\text {low }} \mathrm{CD} 19^{+}$cells) that express $\mathrm{CD} 27$, a marker expressed on activated, antigen-experienced B cells (Figure 3a). These CD27+ proliferating $B$ cells were more prevalent after vaccination than before vaccination for healthy controls (Figure $3 \mathrm{~b}$ ) while an opposite trend was observed for COPD subjects. Furthermore, post vaccination, fewer $\mathrm{CD} 27^{+}$proliferating $\mathrm{B}$ cells were induced in the COPD patients compared to healthy controls (Figure $3 \mathrm{c}$ and $3 \mathrm{~d}, \mathrm{p}=0.04$ ).

\section{Adaptive 'cell-mediated' immune responses to vaccination}

Experiments then examined the capacity of PBMC to produce IFN- $\gamma$ after re-exposure in vitro to the vaccine. PBMC, collected pre and post-vaccination, were stimulated with vaccine for 5-days and IFN- $\gamma$ measured in supernatants. PBMC obtained prior to vaccination 
a

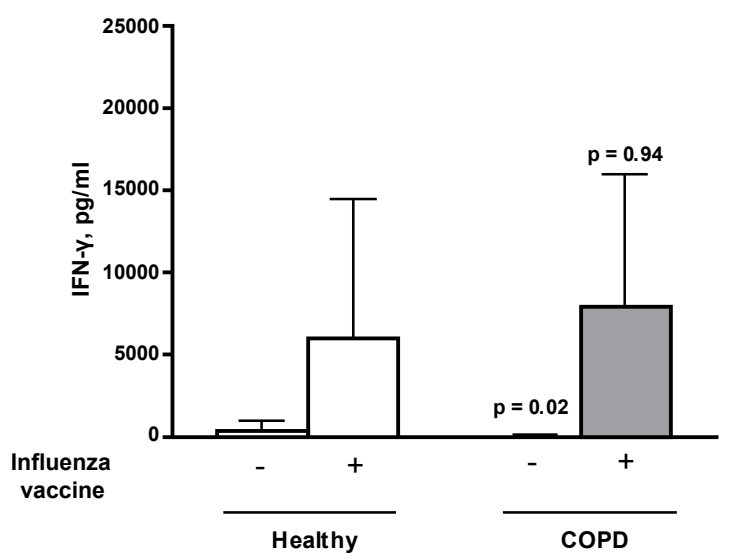

b

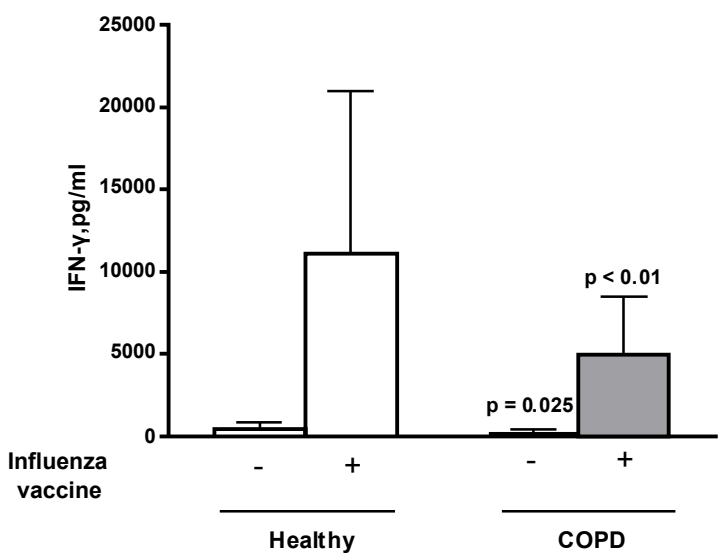

Figure 4: Pre (a) and post (b) vaccination IFN-y synthesis. PBMC were collected before (T0; $n=7$ COPD subjects and 10 healthy controls) and after (T1; $n=19$ COPD subjects and 12 healthy controls) vaccination and cultured in vitro for five days in the presence or absence of influenza vaccine. Results are shown as median \pm IQ. $P$ values refer to the comparison between COPD patients and healthy controls.

produced similar concentrations of IFN- $\gamma$ between COPD subjects and healthy donors (Figure 4a). Post-vaccination, PBMC from COPD subjects produced significantly less IFN- $\gamma$ than PBMC from healthy donors (Figure $4 \mathrm{~b} ; \mathrm{p}<0.01$ ). The Wilcoxon non-parametric paired test showed only vaccine stimulated PBMC from healthy controls produced significant higher amount of IFN $-\gamma$ post vaccination compared to baseline ( $\mathrm{p}=0.016$ and $\mathrm{p}=0.81$ for healthy controls and COPD subjects, respectively). A strong positive correlation was noted between IFN- $\gamma$ and the number of proliferating $B$ cells expressing CD27 in post vaccination PBMC $(\mathrm{R}=0.63, \mathrm{p}<0.01)$. IP-10 production from PBMC collected prior to vaccination was inversely proportional to IFN- $\gamma$ production from $\mathrm{PBMC}$ collected post-vaccination $(\mathrm{R}=-0.56, \mathrm{p}=0.046)$; i.e. the higher the innate immune response at baseline, the lower the IFN- $\gamma$ recall response post vaccination.

\section{Discussion}

The objective of this study was to investigate the immune responses to influenza vaccination in a small cohort of COPD patients compared to healthy controls subjects. Collectively, our data indicate that trivalent inactivated influenza vaccine (at a dose of $15 \mathrm{~g}$ HA per strain) induced an altered humoral and cellular immune response in COPD patients relative to healthy control subjects. COPD patients had lower titres of H1N1 specific Abs and lower serum IL-21 after vaccination than the healthy controls. Vaccine-stimulated PBMC collected pre and postvaccination provided insight into the potential mechanisms leading to the differences in antigenic reactivity. Proliferating B cells expressed the activation marker CD27 to a lesser extent and the capacity of total circulating cells to synthetise IFN- $\gamma$ was reduced, relative to those from healthy subjects. These data suggest a larger study is warranted, as clear differences in immune responses to annual influenza vaccination were found between patients with COPD and healthy individuals in our cohort.

Multivariate analysis of our data indicated that the association between COPD and post vaccination $\mathrm{Ab}$ titres was independent of age. It is well established that influenza vaccine immunogenicity is lower in healthy elderly people than in healthy younger adults [35]. Although healthy individuals were younger than the COPD subjects in our study, it is noteworthy that age did not correlate with post vaccination Ab titre in the healthy individuals. Taken together, these results suggest that age does not explain the reduced $\mathrm{H} 1 \mathrm{~N} 1 \mathrm{Ab}$ titres after influenza vaccination in COPD subjects. This interpretation is supported by our studies of cellular immune function: in a subset of patients and controls who were matched for age we observed reduced B-cell and T-cell function (Figures 3 and 4).

"Original Antigenic Sin" (OAS) has been proposed to explain the observation that individuals appear to be immunologically imprinted according to the first strain of the virus they encounter, often during childhood [36]. The Influenza A/H1N1 subtype was the only strain used to assess $\mathrm{Ab}$ titres in our cohort; however, we doubt that OAS could explain the differences in immune responses observed between COPD patients and control subjects. Influenza $\mathrm{A} / \mathrm{H} 1 \mathrm{~N} 1$ is the only strain in the trivalent influenza vaccine preparation which was circulating before 1957 and as the majority of subjects in our cohort were born prior to this, it is likely that they had been in contact with H1N1 during childhood. It is noteworthy that measurement of only the Influenza A/H1N1 antibody titres in this study does not allow conclusions to be drawn concerning the vaccine immunogenicity and its ability to protect against influenza infection in COPD patients. These results, however, provided evidence of differences in immune responses to vaccination between the study groups, prompting us to further investigate innate and adaptive

\begin{tabular}{|l|c|c|c|}
\hline & Healthy & COPD & p value \\
\hline \multicolumn{1}{|c|}{ mRNA } & \multicolumn{2}{|c|}{ Fold change; median[range] } & \\
\hline IFN $\beta$ & $10.78[0.24-57.1]$ & $4.8[0.01-37.4]$ & 0.33 \\
\hline MxA & $10.39[0.33-83.9]$ & $31.25[0.92-70.0]$ & 0.22 \\
\hline OAS & $16.17[0.35-58.1]$ & $24.85[4.45-49.01]$ & 0.37 \\
\hline IL-12p35 & $3.28[0.29-14.98]$ & $4.98[0.2-10.16]$ & 0.79 \\
\hline \multicolumn{1}{|c|}{ Protein } & Concentration $(\mathrm{pg} / \mathrm{ml}) ;$ median[range] & \\
\hline IFNa & $351.6[22-660]$ & $81[50-1880]$ & 0.24 \\
\hline IP-10 & $38,016[0-103020]$ & $124,741[2570-152540]$ & 0.04 \\
\hline
\end{tabular}

PBMC were stimulated in vitro with influenza vaccine. mRNA and protein levels were measured by GPCR and ELISA, respectively. Fold change was calculated as a ratio to baseline (unstimulated PBMCs) whereas concentration refers only to protein levels in supernatants stimulated with influenza vaccine. IFN- $\alpha$ and IP-10 were barely detectable or undetectable in unstimulated cultures. Results are shown as median \pm IQ; $n=6$ COPD subjects and 10 healthy controls.

Table 3: Innate immune function in healthy subjects and COPD patients. 
immune responses to influenza vaccination in the context of COPD.

Surprisingly, we found little evidence that reduced Influenza A/ H1N1 antibody titres in COPD might be a consequence of deficient innate immune function. We decided to evaluate innate immunity using PBMC collected prior to vaccination, as the process of immunization should have no impact on the amplitude of the innate immune response. Vaccine stimulated cells from COPD patients and healthy controls prior to vaccination exhibited similar expression of multiple innate immune and antiviral genes and synthesised similar amounts of IFN- $\alpha$ protein (Table 3 ). Synthesis of the chemokine IP-10 was actually higher in COPD patients than in healthy controls. Other investigators have reported that various cells from COPD patients can produce considerable amounts of IP-10 [37,38]. We noted that IP-10 synthesis prior to vaccination was inversely proportional to IFN- $\gamma$ production after vaccination, though the explanation for this observation is not apparent.

IL-21 is largely produced by CD4+ T cells [27,28], especially follicular helper T-cells, and is thought to play a critical role in lymph node germinal centre formation and B cell antibody synthesis [39]. Previous studies in HIV infected person have shown that the serum IL-21 concentration after influenza vaccination distinguishes vaccine responders from non-responders [30]. Although we observed no statistical association between serum IL-21 and post-vaccine Ab concentrations, the reduced IL-21 may impact on other aspects of vaccine immunity in COPD including CD8 T-cell memory, IFN- $\gamma$ synthesis and natural killer cell function [27] .

In vitro studies with vaccine stimulated cells demonstrated that proliferating B-cells from COPD patients expressed less CD27, relative to cells from healthy control subjects (Figure 3). CD27 is expressed by memory B cells and is further up-regulated in plasma cells [40]. Proliferating CD19+CD27+ cells are likely to be highly enriched in influenza specific memory B cells. A similar finding was described in patients with non-Hodgkin's lymphoma undergoing influenza vaccination, where $\mathrm{CD} 27+$ memory $\mathrm{B}$ cells were less frequent than in healthy controls [41]. Our results therefore indicate that the function of the peripheral blood B cell compartment differs between COPD subjects and healthy controls.

Furthermore, we found that vaccine stimulated PBMC from COPD subjects synthesized significantly less IFN- $\gamma$ than PBMC from healthy controls. The principal source of this IFN- $\gamma$ is likely to be activated virus specific T cells, rather than natural killer cells. IFN- $\gamma$ is important both for T-cell cytotoxic activity and for enhancing B cell antibody production and antibody class-switching; it has been shown that IFN- $\gamma$ production by PBMC 5 days after in vitro stimulation with influenza vaccine reflects the quality of the adaptive immune response [42] [43]. In our study, the strong correlation between IFN $-\gamma$ production and the number of $\mathrm{CD} 27+$ proliferating $\mathrm{B}$ cells supports the notion that impaired $\mathrm{T}$ cell function is contributing to reduced $\mathrm{B}$ cell activation.

We acknowledge that this work is only a small study due to the low number of subjects and therefore would need to be replicated in a larger cohort. However, based on our statistical analysis, the study was adequately powered for the end points that were studied (statistical power $\mathrm{P}=85 \%$ for post vaccination serum $\mathrm{H} 1 \mathrm{~N} 1 \mathrm{Ab}$ titres; $\mathrm{P}=89 \%$ for post vaccination serum IL-21 titres; $\mathrm{P}=65 \%$ for the frequency of post vaccination proliferating $\mathrm{B}$ cells expressing $\mathrm{CD} 27 ; \mathrm{P}=99 \%$ for post vaccination IFN- $\gamma$ production).

Current clinical guidelines recommend annual trivalent inactivated influenza vaccine for individuals with chronic respiratory diseases such as COPD. The findings of the current study do not justify changing these recommendations. Though the immune reactivity to influenza vaccine was partly reduced in COPD patients, the majority of study participants had post-vaccination titres of $\mathrm{H} 1 \mathrm{~N} 1$ antibodies that are associated with seroprotection. Nonetheless we suggest that further investigations are warranted to examine the mechanisms behind our observations and potential new vaccination approaches in COPD, in order to maximise the protection against severe seasonal influenza infections. While live attenuated vaccines might be expected to elicit stronger T-cell responses than an inactivated vaccine, studies in older adults who have previously been vaccinated or exposed to natural influenza infection do not support this approach [44]. Increasing the dose of trivalent inactivated influenza vaccine might enhance immunogenicity in COPD, especially as higher dose vaccine has been shown to improve seroprotection rates in severe asthma [45] and in healthy elderly people [46]; adjuvants can also improve vaccine immunogenicity [47]. These approaches are worthy of further investigation in COPD.

In conclusion, our study indicates that trivalent inactivated influenza vaccine is associated with reduction in serum $\mathrm{A} / \mathrm{H} 1 \mathrm{~N} 1$ antibody titres and IL-21, impaired B-cell activation and lower IFN- $\gamma$ synthesis after vaccination, thus providing insight into the molecular and cellular mechanisms underlying immune function in COPD.

\section{Acknowledgements}

The authors would like to thank Dr. Sebastien Bertin-Maghit for his helpful advice (Singapore Immunology Network).

This work was supported by the National Health and Medical Research Council, Australia and the Princess Alexandra Hospital Foundation.

\section{References}

1. World Health Organization (2004) Programmes and projects - Chronic Obstructive Pulmonary Disease.

2. Varkey JB, Varkey AB, Varkey B (2009) Prophylactic vaccinations in chronic obstructive pulmonary disease: current status. Curr Opin Pulm Med 15: 90-99.

3. McManus TE, Marley AM, Baxter N, Christie SN, O'Neill HJ, et al. (2008) Respiratory viral infection in exacerbations of COPD. Respir Med 102: 15751580 .

4. Varkey JB, Varkey B (2008) Viral infections in patients with chronic obstructive pulmonary disease. Curr Opin Pulm Med 14: 89-94.

5. Vozoris NT, Lougheed MD (2009) Influenza vaccination among Canadians with chronic respiratory disease. Respir Med 103: 50-58.

6. Pesek R, Lockey R (2011) Vaccination of adults with asthma and COPD Allergy 66: 25-31.

7. Global Strategy for the Diagnosis (2011) Management and Prevention of COPD, Global Initiative for Chronic Obstructive Lung Disease (GOLD).

8. Australian and New Zealand guidelines for the management of Chronic Obstructive Pulmonary disease (2011)

9. Nichol KL, Baken L, Nelson A (1999) Relation between influenza vaccination and outpatient visits, hospitalization, and mortality in elderly persons with chronic lung disease. Ann Intern Med 130: 397-403.

10. Vila-Corcoles A, Ochoa O, de DC, Valdivieso A, Herreros I, et al. (2008) Effects of annual influenza vaccination on winter mortality in elderly people with chronic pulmonary disease. Int J Clin Pract 62: 10-17.

11. Eurich DT, Marrie TJ, Johnstone J, Majumdar SR (2008) Mortality reduction with influenza vaccine in patients with pneumonia outside "flu" season: pleiotropic benefits or residual confounding? Am J Respir Crit Care Med 178: 527-533.

12. Jackson LA, Nelson JC, Benson P, Neuzil KM, Reid RJ, et al. (2006) Functional status is a confounder of the association of influenza vaccine and risk of all cause mortality in seniors. Int J Epidemiol 35: 345-352.

13. Simonsen L, Taylor RJ, Viboud C, Miller MA, Jackson LA (2007) Mortality benefits of influenza vaccination in elderly people: an ongoing controversy. Lancet Infect Dis 7: 658-666. 
Citation: Burel JG, Nath K, Pritchard AL, White OJ, Davies JM, et al. (2012) Evaluation of Immune Responses to Influenza Vaccination in Chronic Obstructive Pulmonary Disease. J Vaccines Vaccin S4:001. doi:10.4172/2157-7560.S4-001

14. Jackson LA, Jackson ML, Nelson JC, Neuzil KM, Weiss NS (2006) Evidence of bias in estimates of influenza vaccine effectiveness in seniors. Int $\mathrm{J}$ Epidemiol 35: $337-344$.

15. Poole PJ, Chacko E, Wood-Baker RW, Cates CJ (2006) Influenza vaccine for patients with chronic obstructive pulmonary disease. Cochrane Database Syst Rev: CD002733.

16. Howells CH, Tyler LE (1961) Prophylactic use of influenza vaccine in patients with chronic bronchitis. A pilot trial. Lancet 2: 1428-1432.

17. Wongsurakiat P, Maranetra KN, Wasi C, Kositanont U, Dejsomritrutai W, et al (2004) Acute respiratory illness in patients with COPD and the effectiveness of influenza vaccination: a randomized controlled study. Chest 125: 2011-2020.

18. Woodland DL, Hogan RJ, Zhong W (2001) Cellular immunity and memory to respiratory virus infections. Immunol Res 24: 53-67.

19. Beyer WE, Palache AM, Luchters G, Nauta J, Osterhaus AD (2004) Seroprotection rate, mean fold increase, seroconversion rate: which parameter adequately expresses seroresponse to influenza vaccination? Virus Res 103: 125-132.

20. Halliley JL, Kyu S, Kobie JJ, Walsh EE, Falsey AR, et al. (2010) Peak frequencies of circulating human influenza-specific antibody secreting cells correlate with serum antibody response after immunization. Vaccine 28: 3582 3587.

21. Lee FE, Halliley JL, Walsh EE, Moscatiello AP, Kmush BL, et al. (2011) Circulating human antibody-secreting cells during vaccinations and respiratory viral infections are characterized by high specificity and lack of bystander effect. J Immunol 186: 5514-5521.

22. Brown DM, Roman E, Swain SL (2004) CD4 T cell responses to influenza infection. Semin Immunol 16: 171-177.

23. He XS, Mahmood K, Maecker HT, Holmes TH, Kemble GW, et al. (2003) Analysis of the frequencies and of the memory $T$ cell phenotypes of human CD8+ T cells specific for influenza A viruses. J Infect Dis 187: 1075-1084.

24. Kreijtz JH, Fouchier RA, Rimmelzwaan GF (2011) Immune responses to influenza virus infection. Virus Res 162: 19-30.

25. Julkunen I, Sareneva T, Pirhonen J, Ronni T, Melen K, et al. (2001) Molecular pathogenesis of influenza A virus infection and virus-induced regulation of cytokine gene expression. Cytokine Growth Factor Rev 12: 171-180.

26. Coffman RL, Sher A, Seder RA (2010) Vaccine adjuvants: putting innate immunity to work. Immunity 33: 492-503.

27. Rodrigues L, Bonorino C (2009) Role of IL-15 and IL-21 in viral immunity: applications for vaccines and therapies. Expert Rev Vaccines 8: 167-177.

28. Dienz O, Eaton SM, Bond JP, Neveu W, Moquin D, et al. (2009) The induction of antibody production by IL- 6 is indirectly mediated by IL-21 produced by CD4+ T cells. J Exp Med 206: 69-78.

29. Avery DT, Bryant VL, Ma CS, de WMR, Tangye SG (2008) IL-21-induced isotype switching to IgG and IgA by human naive $B$ cells is differentially regulated by IL-4. J Immunol 181: 1767-1779.

30. Pallikkuth S, Pilakka KS, Silva SY, Fischl M, Pahwa R, et al. (2011) Upregulation of IL-21 receptor on B cells and IL-21 secretion distinguishes novel 2009 H1N1 vaccine responders from nonresponders among HIV-infected persons on combination antiretroviral therapy. J Immunol 186: 6173-6181.

31. Roponen M, Yerkovich ST, Hollams E, Sly PD, Holt PG, et al. (2010) Toll-like receptor 7 function is reduced in adolescents with asthma. Eur Respir $\mathrm{J} 35$ 64-71.

32. Quah BJ, Warren HS, Parish CR (2007) Monitoring lymphocyte proliferation in vitro and in vivo with the intracellular fluorescent dye carboxyfluorescein diacetate succinimidyl ester. Nat Protoc 2: 2049-2056.
33. Schandene L, Del Prete GF, Cogan E, Stordeur P, Crusiaux A et al. (1996) Recombinant interferon-alpha selectively inhibits the production of interleukin-5 by human CD4+ T cells. J Clin Invest 97: 309-315.

34. Pfaffl MW (2001) A new mathematical model for relative quantification in realtime RT-PCR. Nucleic Acids Res 29: e45.

35. Goodwin K, Viboud C, Simonsen L (2006) Antibody response to influenza vaccination in the elderly: a quantitative review. Vaccine 24: 1159-1169.

36. Dormitzer PR, Galli G, Castellino F, Golding H, Khurana S, et al. (2011) Influenza vaccine immunology. Immunol Rev 239: 167-177.

37. Schneider D, Ganesan S, Comstock AT, Meldrum CA, Mahidhara R, et al. (2010) Increased cytokine response of rhinovirus-infected airway epithelial cells in chronic obstructive pulmonary disease. Am J Respir Crit Care Med 182 332-340.

38. Costa CH, Rufino R, Lapa ESJR (2009) [Inflammatory cells and their mediators in COPD pathogenesis]. Rev Assoc Med Bras 55: 347-354

39. Zotos D, Coquet JM, Zhang Y, Light A, D'Costa K, et al. (2010) IL-21 regulates germinal center $B$ cell differentiation and proliferation through a B cell-intrinsic mechanism. J Exp Med 207: 365-378.

40. Avery DT, Ellyard JI, Mackay F, Corcoran LM, Hodgkin PD, et al. (2005) Increased expression of CD27 on activated human memory B cells correlates with their commitment to the plasma cell lineage. J Immunol 174: 4034-4042.

41. Bedognetti D, Zoppoli G, Massucco C, Zanardi E, Zupo S, et al. (2011) Impaired response to influenza vaccine associated with persistent memory $B$ cell depletion in non-Hodgkin's lymphoma patients treated with rituximabcontaining regimens. J Immunol186: 6044-6055.

42. Toapanta FR, Ross TM (2009) Impaired immune responses in the lungs of aged mice following influenza infection. Respir Res10: 112.

43. Mbawuike I, Zang Y, Couch RB (2007) Humoral and cell-mediated immune responses of humans to inactivated influenza vaccine with or without QS21 adjuvant. Vaccine 25: 3263-3269.

44. Gorse GJ, O'Connor TZ, Young SL, Mendelman PM, Bradley SF, et al. (2003) Efficacy trial of live, cold-adapted and inactivated influenza virus vaccines in older adults with chronic obstructive pulmonary disease: a VA cooperative study. Vaccine 21: 2133-2144.

45. Busse WW, Peters SP, Fenton MJ, Mitchell H, Bleecker ER, et al. (2011) Vaccination of patients with mild and severe asthma with a 2009 pandemic H1N1 influenza virus vaccine. J Allergy Clin Immunol 127: 130-137, 137.e1-3.

46. Falsey AR, Treanor JJ, Tornieporth N, Capellan J, Gorse GJ (2009) Randomized double-blind controlled phase 3 trial comparing the immunogenicity of highdose and standard-dose influenza vaccine in adults 65 years of age and older. J Infect Dis 200: 172-180.

47. Baldo V, Baldovin T, Floreani A, Carraro AM, Trivello R (2007) MF59adjuvanted influenza vaccine confers superior immunogenicity in adult subjects (18-60 years of age) with chronic diseases who are at risk of post-influenza complications. Vaccine 25: 3955-3961. 